\title{
Securing the Downside Up: Client and Care Factors Associated with Outcomes of Secure Residential Youth Care
}

\author{
Annemiek T. Harder • Erik J. Knorth • Margrite E. Kalverboer
}

Published online: 26 November 2011

(C) The Author(s) 2011. This article is published with open access at Springerlink.com

\begin{abstract}
Background Although secure residential care has the potential of reducing young people's behavioral problems, it is often difficult to achieve positive outcomes. Research suggests that there are several common success factors of treatment, of which the client's motivation for treatment and the quality of the therapeutic relationship between clients and therapists might be especially relevant and important in the context of secure residential care.

Objective The objective of the present study was to explore the association of these potential success factors with secure residential care outcomes.

Methods A repeated measures research design was applied in the study, including a group of adolescents in a secure residential care center that was followed up on three measurements in time. Interviews and questionnaires concerning care outcomes in terms of adolescents' behavior change during care were administered to 22 adolescents and 27 group care workers. Outcomes in terms of adolescents' treatment satisfaction were assessed by the use of questionnaires, which were completed by 51 adolescents.

Results Adolescents reported some positive changes in their treatment motivation, but those who were more likely to be motivated at admission were also more likely to deteriorate in treatment motivation from admission to departure. Treatment satisfaction was associated with better treatment motivation at admission and with a positive adolescentgroup care worker relationship.

Conclusions The results suggest that outcomes can be improved by a more explicit treatment focus on improving the adolescent's treatment motivation and the quality of the adolescent-care worker relationship during secure residential care.
\end{abstract}

Keywords Secure residential care $\cdot$ Adolescents $\cdot$ Process of care $\cdot$ Outcomes

\footnotetext{
A. T. Harder $(\bowtie) \cdot$ E. J. Knorth · M. E. Kalverboer

Faculty of Behavioral and Social Sciences, Department of Special Needs Education and Youth Care, University of Groningen, Groote Rozenstraat 38, 9712 TJ Groningen, The Netherlands

e-mail: A.T.Harder@rug.nl
} 


\section{Introduction}

Research suggests that the problem behavior of young people in secure residential care, which often includes delinquency, is quite stable over time. Secure residential care can be seen as the most intensive or restrictive type of residential care, and refers to a type of service in which young people, who are often placed under coercion, receive care and treatment in a secured environment. While youth still regularly show problem behavior after their departure, secure residential care has more positive outcomes on the short term: young people often improve in their functioning during secure residential care (Knorth et al. 2008). However, outcomes of secure residential youth care are often described in terms of delinquent behavior (cf. Abrams 2006; Genovés et al. 2006). Meta-analyses show that treatment of delinquent youth in residential care leads to an average reduction of recidivism by about 9\% (Grietens and Hellinckx 2004). These findings indicate that (secure) residential care has the potential of reducing problem behavior, but that it is often difficult to achieve.

The most important predictors of outcomes in child and youth care are considered to be non-specific or common client and relationship factors, which affect the services offered regardless of the target group or the type of services (Carr 2009; Karver et al. 2006). According to this common process factors model (Karver et al. 2005), client factors consist of the factors that are part of the client, such as the severity of the problems, the clients' strengths and motivation for treatment, and factors that are part of their context, such as social support in their environment. Relationship factors refer to the therapeutic relationship, which is most commonly defined as an emotional connection (e.g. affective attachment, affective bond, social support) and/or a cognitive connection in terms of agreement on the tasks and goals of treatment between a client and a therapist (Karver et al. 2005).

Because adolescents in secure residential care typically are not self-referred and often enter into treatment poorly aware of their problems, resistant to change, and/or in conflict with their parents, client and relationship factors seem to be especially important in the context of secure residential care (cf. Karver et al. 2006; Van Binsbergen et al. 2004). In the first place, a lack of motivation for treatment is often considered to be a characteristic of young people in secure residential care (Van Binsbergen 2003). Research has also shown that the young people's motivation for treatment is among the most important client factors that are associated with the therapeutic relationship and outcomes of youth care (Karver et al. 2005, 2006). Secondly, research results have indicated that there is a strong association between the quality of the client-therapist relationship and treatment outcomes for young people with externalizing problems (Shirk and Karver 2003). More specifically, young people with externalizing behavior problems regularly show difficulties in treatment engagement and alliance formation. Since young people with externalizing behavior problems are often strongly represented in secure residential care (Bullock et al. 1998), the formation of a therapeutic relationship with young people may be particularly challenging and critical for the outcomes that can be achieved in secure residential care (cf. Shirk and Karver 2003).

Despite the relevance of treatment motivation in association with the therapeutic relationship and outcomes that can be achieved, there are very few studies that have looked at the association between young people's motivation for treatment and outcomes of secure residential youth care (cf. Englebrecht et al. 2008). The one study that we found shows that youth in secure residential care who have a higher level of motivation for treatment show better outcomes in terms of retention than youth with a low level of motivation (Orlando et al. 2003). Research also shows that motivation for treatment of the young people can be 
developed during secure residential care, although a functional therapeutic relationship to promote motivation for treatment is more difficult to establish with youth showing serious psychopathology than with youth showing less serious psychopathology (Van Binsbergen 2003).

A more positive relationship between youth and therapists is associated with positive outcomes in terms of more satisfaction of young people regarding treatment (Marsh et al. 2010; Ramos et al. 2006; Van Yperen 2003). Within the context of juvenile correction settings, Marsh et al. (2010) found for example that young people who experienced positive relationships with staff in terms of high levels of trust and affect, effective problem solving, and engagement, more often felt comfortable and accepted in the program than young people who did experience less positive relationships with staff.

Research also indicates that the relationship between therapists and young people in care has an important role in association with poor outcomes, such as drop-out of care (cf. Garcia and Weisz 2002; Robbins et al. 2003). Dropping-out of care seems to be quite common in residential youth care (e.g., Kashubeck et al. 1994; Klingsporn et al. 1990; Sunseri 2001). For example, numbers of 110 studies describing empirical research on outcomes of residential youth care show that on average $24 \%$ of the young people in almost a third of the studies (30\%) dropped-out of care (Harder et al. 2006; Knorth et al. 2008). Young people that drop out of residential care show more negative outcomes than youth who do not leave care prematurely, and this seems to be especially true for young people who are unmotivated for treatment, inaccessible for staff, and who show problematic behavior while in care (Harder et al. 2011a, b; Van der Ploeg et al. 2000).

Of the few studies that have looked at the association between the client-staff relationship and outcomes in the context of secure residential youth care, two studies did not find an association between the adolescent-staff relationship and outcomes in terms of change in the young people's problem behavior (Holmqvist et al. 2007; Zegers 2007). One study that did found a positive association between a good client-staff relationship and reduction of problem behavior during care indicated that the establishment of a positive relationship with the most severely delinquent youth is problematic (Florsheim et al. 2000). Florsheim et al. (2000) also concluded that the development of the relationship over time seems to be of more importance for obtaining positive outcomes than the absolute value of the relationship between youth and staff shortly after admission. With regard to the situation of young people after their departure from secure residential care, Marsh and Evans (2009) found that young people who experienced positive relationships with care workers perceived the greatest likelihood of success on departure in terms of potential for success, social networks, substance abuse/reoffending and conflict reduction.

Given the difficulties in achieving positive outcomes with adolescents in secure residential care, and the small amount of research that exists on potential success factors (cf. Bettmann and Jasperson 2009; Knorth et al. 2008), the purpose of the present study was to assess specific client and care process characteristics that may be associated with successful outcomes in secure residential youth care.

Specifically, the first objective of the study was to assess the outcomes of secure care in terms of adolescents' behavior change during care and their treatment satisfaction with regard to different care aspects. With regard to these outcomes, an important purpose of this study was to test whether most of the adolescents would show improvements in their functioning during their stay in secure residential care (cf. Knorth et al. 2008). More specifically, we tested whether adolescents showed improvements in their motivation for treatment and competence skills, because the secure care center in the present study mainly 
intervened with the motivation for treatment and competence skills of the adolescents (Harder et al. 2007).

A second objective was to identify whether and how the adolescents' behavior problems at admission, and the quality of the client-staff relationship were associated with adolescents' behavior change and treatment satisfaction. We tested whether adolescents who were motivated for treatment, who showed relatively few behavior problems at admission and experienced a good relationship with staff during their stay, had more positive outcomes than adolescents with a poor treatment motivation, many behavior problems and a poor relationship with staff (cf. Orlando et al. 2003). Adolescents' behavior problems were assessed in terms of a distinction in four risk groups within the present sample that were found in a previous study (see Harder et al. 2011a, b). These subgroups were based on a combination of treatment motivation with other important dynamic risk factors, such as substance abuse, poor parental supervision and having delinquent friends (DeMatteo and Marczyk 2005), and were found to show significant differences regarding the seriousness and type of problems. The groups included a (1) low risk, (2) individual risk, (3) individual and family risk, and (4) high risk group.

\section{Method}

Participants

Adolescents staying in Het Poortje, which is a secure residential center in the Netherlands, participated in the study. Adolescents from 12 to 23 years old were often coercively placed in the center by either a civil or penal measure. Adolescents were eligible for inclusion if they entered the center between 1 September 2007 and 1 June 2008, were able to understand the Dutch language, stayed for a minimum period of 8 weeks and had left the center. These criteria resulted in a group of 180 adolescents that was eligible for inclusion.

For this study we used information from somewhat different subsamples within the total research sample. To view changes in adolescents' behaviour from admission $\left(\mathrm{T}_{1}\right)$ to departure $\left(\mathrm{T}_{3}\right)$, we used two samples. The first sample consisted of 22 adolescents for whom there was information about outcomes in terms of change in treatment motivation. The second sample was a group of 27 group care workers that completed a questionnaire about the adolescents' competence skills.

Since there often was no information about the exact moment of departure and the moment of departure in most cases just became clear after the young person had already left the center, it was problematic to get into contact with the adolescents for administering the interviews and questionnaires at departure. Due to this fact, 31 adolescents $(17 \%)$ completed questionnaires on average 6.9 weeks after their departure, of whom 22 adolescents had also completed the questionnaires at admission. Parallel to this group of adolescents, 44 group care workers $(24 \%)$ completed questionnaires on average 1.9 weeks after the adolescents' departure, resulting in a group of 27 group care workers that completed the questionnaire about the adolescents' competence skills at admission and departure.

Information on adolescents' demographic and problem characteristics at the moment of admission for these two samples (i.e., 22 adolescents and 27 group care workers) are shown in Table 1.

Since we experienced attrition with regard to both the adolescents' and group care workers' information, we additionally examined a possible attrition bias. Therefore, we looked at differences between the response and non-response groups in terms of 
Table 1 Adolescents' characteristics for adolescent and coach response groups

\begin{tabular}{|c|c|c|c|c|}
\hline \multirow{2}{*}{$\begin{array}{l}\text { Characteristic } \\
\text { Age at admission }\end{array}$} & \multicolumn{2}{|c|}{$\begin{array}{l}\mathrm{T}_{1}-\mathrm{T}_{3} \text { motivation } \\
\text { adolescents }(\mathrm{n}=22)\end{array}$} & \multicolumn{2}{|c|}{$\begin{array}{l}\mathrm{T}_{1}-\mathrm{T}_{3} \text { competence } \\
\text { coaches }(\mathrm{n}=27)\end{array}$} \\
\hline & $\begin{array}{l}M \\
16.2 \\
N\end{array}$ & $\begin{array}{l}\text { SD (range) } \\
1.6(13.4-20.0) \\
\%\end{array}$ & $\begin{array}{l}M \\
16.3 \\
N\end{array}$ & $\begin{array}{l}\text { SD (range) } \\
1.3(13.2-18.3) \\
\%\end{array}$ \\
\hline Male (vs. female) & 15 & 68.2 & 20 & 74.1 \\
\hline Dutch origin (vs. non-Dutch origin) & 16 & 72.7 & 18 & 66.7 \\
\hline Civil placement measure (vs. penal) & 17 & 73.9 & 21 & 77.8 \\
\hline Living close by the center (vs. further away) & $10^{\mathrm{a}}$ & 52.6 & 17 & 63.0 \\
\hline \multicolumn{5}{|l|}{ Living arrangement before admission ${ }^{\mathrm{b}}$} \\
\hline At home with (one of the) parents & 6 & 30.0 & 13 & 50.0 \\
\hline Residential setting (incl. secure) & 9 & 45.0 & 9 & 34.6 \\
\hline Living with (foster)family & 4 & 20.0 & 1 & 3.8 \\
\hline Independent & 2 & 5.0 & 2 & 7.7 \\
\hline Instable/homeless & 0 & 0 & 1 & 3.8 \\
\hline Care history before admission & 22 & 95.5 & 26 & 96.3 \\
\hline Externalising behavior problems & 19 & 81.8 & 26 & 96.3 \\
\hline Internalising behavior problems & 9 & 40.9 & 11 & 40.7 \\
\hline Delinquent behavior & $9^{c}$ & 45.0 & 21 & 77.8 \\
\hline
\end{tabular}

There is an overlap of five adolescents between the two groups

${ }^{\mathrm{a}} n=19,{ }^{\mathrm{b}} n_{\text {group } 1}=20$ and $n_{\text {group } 2}=26,{ }^{\mathrm{c}} n=20$

background (see Table 1) and relevant characteristics that were known for most of the adolescents (e.g., the client-staff relationship, adolescents' motivation for treatment and competence skills at admission). Results of these analyses showed that the adolescents' response group significantly less often stayed with parents, $\chi^{2}(1)=4.6, p=.035$, and less often showed delinquent behavior before admission, $\chi^{2}(1)=9.0, p=.005$, than the nonresponse group. The response and non-response coach groups did not significantly differ, although there was a trend $(p=.096)$ for adolescents in this response group to report a poorer relationship with their mentor than the non-response group, $U=720.5, z=-1.67$, $r=.15$. These results indicate that the adolescent response group is less problematic than the non-response groups. For the group of 27 adolescents for whom there was care workers information, we found no indications for an attrition bias.

To view outcomes in terms of adolescents' treatment satisfaction, we used a sample of 51 adolescents (28\%) that completed a questionnaire on average 10.1 weeks after their admission. Demographic and problem characteristics of these 51 adolescents are shown in Table 2.

Just as for the previous two samples, we examined a possible attrition bias. We found that the response group seemed to be less problematic than the non-response groups, because the response group reported significantly higher motivation for treatment scores at admission, $U=896.0, \mathrm{z}=-2.52, r=.24, p=.011$, and was less likely than the nonresponse group to show delinquent behavior before admission, $\chi^{2}(1)=3.7, p=.059$.

\section{Procedure}

The present study was part of a practice-based research project which focuses on adolescents staying in a secure residential center in the Netherlands. The total research project 
Table 2 Adolescents' characteristics for the satisfaction response group $(n=51)$

\begin{tabular}{llc}
\hline Characteristic & $M$ & SD (range) \\
Age at admission & 16.0 & $1.6(12.4-20.0)$ \\
& $N$ & 64.7 \\
\hline Male (vs. female) & 33 & 64.7 \\
Dutch origin (vs. non-Dutch origin) & 33 & 76.5 \\
Civil placement measure (vs. penal) & 39 & 42.9 \\
Living close by the center (vs. further away) & $21^{\mathrm{a}}$ & \\
Living arrangement before admission ${ }^{\mathrm{b}}$ & & 51.0 \\
At home with (one of the) parents & 25 & 34.7 \\
Residential setting (including secure) & 17 & 12.2 \\
Living with (foster)family & 6 & 2.0 \\
Independent & 1 & 0 \\
Instable/homeless & 0 & 93.9 \\
Care history before admission & $46^{\mathrm{a}}$ & 90.2 \\
Externalising behavior problems & 46 & 37.3 \\
Internalising behavior problems & 19 & 62.5 \\
Delinquent behavior & $30^{\mathrm{c}}$ & \\
\hline
\end{tabular}

${ }^{\mathrm{a}} n=49,{ }^{\mathrm{b}} n=49,{ }^{\mathrm{c}} n=48$

had a longitudinal repeated measures research design with four moments of measurement: at admission $\left(\mathrm{T}_{1}\right), 8$ weeks after admission $\left(\mathrm{T}_{2}\right)$, at departure $\left(\mathrm{T}_{3}\right)$ and 1 year after departure $\left(T_{4}\right)$. The present study was based on data collected at $T_{1}, T_{2}$ and $T_{3}$.

In the first place, we used information from questionnaires administered with adolescents and group care workers at admission $\left(T_{1}\right)$ and departure $\left(T_{3}\right)$ to view outcomes in terms of changes in adolescents' behavior (i.e., treatment motivation and competence skills) from $T_{1}$ to $T_{3}$. Secondly, we used information of $T_{2}$ questionnaires from the adolescents to view outcomes in terms of their treatment satisfaction. In the third place, we used information from questionnaires completed by the adolescents at admission $\left(\mathrm{T}_{1}\right)$ to assess their treatment motivation. Fourth, we used information from interviews administered with adolescents and questionnaires administered with group care workers and teachers 8 weeks after admission $\left(\mathrm{T}_{2}\right)$ with regard to the adolescent-staff relationships.

The adolescents were informed about the research project by the project leader shortly after their admission during a private conversation at the center and by an information flyer. To promote their participation in the project, it was emphasized that participation in the project was confidential and that it was a common part of their stay in the center. Once the adolescent agreed to participate, the project leader informed one of the interviewers so that he or she could contact the youth for the interviews. These interviews were carried out by students of the University of Groningen using (semi-) structured interviews. During these interviews, no other persons were present. To guarantee a correct administration, these students received training before conducting the interviews. Besides interviews, the adolescents completed the questionnaires in their own time during their stay in the center.

Group care workers and teachers, or more specifically the so-called coach and mentor of the adolescent, were approached by e-mail with a short explication about the purpose of the study and the questionnaires in an attachment, which they could fill in digitally or manually and reply by (e-)mail. The coach was one of the group care workers of the residential group and the mentor one of the teachers at the internal school whom the adolescents could turn 
to when they were in need of help and advice. Before approaching them individually, the group care workers and teachers were also informed about the research project by the project leader during several group meetings at the center.

Both the adolescents, group care workers and teachers were treated in accordance with the Ethical Principles of Psychologists and Code of Conduct (American Psychological Association 2002).

\section{Nature of the Residential Program}

Secure residential care center Het Poortje is a private care center that is located on two locations in the north of the Netherlands. The center functions within the context of both child welfare and juvenile justice. During the research project, it consisted of a department with eight residential groups and a department with twelve residential groups. The secure residential center offered care and treatment for adolescents in a secured or locked environment for $24 \mathrm{~h}$ a day. Most of the adolescents only had permission to exit the center under supervision.

The principal reason for admission was either intolerably disruptive and antisocial behavior or behavior presenting a danger to the young person him or herself or to the general public. The center admitted both young people that were awaiting trial or had been convicted for offences (e.g., penal placements) and young people that were at risk for deteriorating in their behavioral and/or emotional problems (e.g., civil placements). The primary target group for admission were young people from proximal home communities. The central goal of the care offered in the center was that the young people would leave the center in a better condition than at entry.

More specifically, the underlying methodology of the care and treatment in the secure center was considered to be the social competency model (Durrant 1993; Slot and Spanjaard 1999). This model aims to reduce young people's problem behavior by enhancing their competence skills. Competence skills are skills that are necessary to complete developmental tasks. These developmental tasks are normative demands and expectations that depend on the age of the young people. Competence can be considered as a balance tasks and skills, which is often upset for the young people admitted to the center. An important aspect of the model is that it is based on the social learning theory and focuses on the stimulation of adequate behavior and on the ignorance of inadequate behavior.

Another underlying theory of the care program at the moment of data collection was the motivation for treatment model of Prochaska and DiClemente (1984). That model assumes that treatment motivation can be improved and consists of several stages of change, namely (1) precontemplation, (2) contemplation, (3) preparation, (4) action, (5) maintenance and (6) relapse. A central focus in the program was to motivate the young people to change their behavior and to improve the insight in their own behavior (Harder et al. 2007).

The main components of care and treatment in the center were activities at the (mostly secured) residential groups and education in special education classes. At the moment of data collection, many adolescents stayed on residential groups with a maximum of twelve adolescents, supported by two group care workers on a daily basis. For each group there was a team of ten to twelve care workers who worked in morning and evening shifts of $8 \mathrm{~h}$. The classes consisted of eight to ten adolescents at the internal school, where they receive training by one teacher. All the group care workers and teachers in the center had to dispose of a so-called "Testimonial of good conduct" before they were hired for work in the center. 
During their stay in the center, each adolescent was assigned to a coach and a mentor. As was mentioned previously, the coach is one of the care workers of the residential group and the mentor is one of the teachers of the adolescent at the internal school. The assignment to care workers and teachers as coach and mentor respectively was unsystematic and mainly based on the order of placement. Both the coach and mentor were responsible for observing the adolescents and were involved in the adolescents' individual treatment planning. For example, besides the activities at the residential group and in the classes, some of the adolescents received additional, individualized counseling. The treatment planning consisted of individualized care plans, which were developed collaboratively by the coach/mentor and clinicians at the center. These care plans were reviewed on a 6 weeks basis.

\section{Measures}

\section{Adolescent-Staff Relationship}

To assess the quality of adolescent-staff relationship, we used information from Psychological Availability and Reliance on Adult (PARA, Schuengel and Zegers 2003) interviews with the adolescents and questionnaires completed by the group care workers and teachers. By using the PARA we assessed the adolescent's experiences in their relationship with their coach and mentor and vice versa. The PARA contains 19 items with a 4-point Likert scale ranging from 1 (disagree) to 4 (agree). For the present study, we calculated a total mean score for an overall indication of the quality of the relationship. In accordance to Schuengel and Zegers (2003), we assume that scale scores lower than 2,5 indicate that the adolescent or staff do not subscribe the viewpoint regarding the relationship, and that scores equal to and above 2,5 do so. We found satisfactory reliability scores for both the adolescent $(\alpha=.85-.91)$ and adult PA and RA scales $(\alpha=.69-.94)$.

\section{Motivation for Treatment}

To evaluate the adolescents' motivation for treatment, the Motivation for Treatment questionnaire (MTQ, Van Binsbergen 2003) was completed by the adolescents. Aim of the instrument is to assess the first three stages of treatment motivation (i.e., precontemplation, contemplation and preparation) that are distinguished by Prochaska and DiClemente (1984). The original version of the MTQ consisted of 81 items, but for the present study we only used a short 17-item version of the questionnaire based on outcomes of factor-analysis conducted by Van Binsbergen (2003). The items of the MTQ contain a 3-point rating scale ranging from 0 (not true) to 2 (true). On the basis of the three subscale scores a total motivation score was calculated by weighing the scores on the stages of motivation as one, two and three respectively, resulting in a range of scores from 0 (not motivated) to 12 (motivated). Total median scores of 6,5 or higher can be perceived as being motivated. Reliability scores $(\alpha=.73-.77)$ of the MTQ for the present sample were satisfactory.

\section{Adolescents' Competence Skills}

For the evaluation of the adolescents' competencies, the Adolescents' Tasks and Skills Questionnaire (TASQ) was completed by the coaches. The TASQ was developed within the scope of a $\mathrm{PhD}$ project in a Dutch secure residential child and youth care setting 
(Van der Knaap 2003). Aim of the instrument is to assess the degree to which a youngster's functioning is adaptive or effective in relation to salient developmental tasks, as judged by a group care worker. The TASQ consists of 137 items concerning the adolescents' skills, plus an appendix questionnaire of 18 items concerning skills regarding the secure care context. All the items contain a 5-point Likert scale ranging from 1 (totally not applicable) to 5 (totally applicable). The questionnaire consists of 29 subscales and six dimensions of competence containing 25 of the 29 subscales. The six broad dimensions include: (1) peer relationships (29 items); (2) autonomy and self-management (24 items); (3) academic competence; (4) job competence; (5) sexuality and relationships; and (6) personal hygiene and well-being. A mean score can be calculated for each dimension, and for the present study we also calculated a mean total competence score based on these six dimensions. A mean total score that is equal or higher than the median of 3 is perceived as sufficient competency. We could not calculate reliability scores due to missing items that resulted in a very small sample. However, for a sample of 184 young people in residential care in the study of Van der Knaap (2003) the internal consistency of the TASQ was satisfactory $(\alpha=.76-.92)$.

\section{Treatment Satisfaction}

The C-test questionnaire (Jurrius et al. 2007) was used to assess the adolescents' satisfaction about the care they received from the secure care center. This 27 -item questionnaire aims to measure client satisfaction in child and youth care. It contains five subscales, a blank subscale which can be filled in with items that are relevant for the specific care setting, and a report mark concerning the treatment satisfaction that ranges from 1 to 10 . The subscales measure the following dimensions of treatment satisfaction: (1) contact and treatment by the therapist (five items) (2) professionalism of the therapist (four items), (3) the course of treatment (four items), (4) receipt of information during care (four items), and (5) goal attainment (four items). Items are scored on a 4-point scale ranging from 1 (totally disagree) to 4 (totally agree). Based on all item scores a total mean satisfaction score can be calculated, which is perceived as sufficient if it is equal or above the mean score of 2,5. The report mark is sufficient if the score is 5,5 or higher. All the subscales showed good reliability $(\alpha=.82-.92)$, except for the receipt of information scale $(\alpha=.67)$ which could be considered acceptable.

\section{Data Analysis}

Outcomes in terms of change in adolescent's motivation for treatment and competence from admission $\left(\mathrm{T}_{1}\right)$ to departure $\left(\mathrm{T}_{3}\right)$ were assessed by using the Wilcoxon signed-rank test. The threshold for significance in these analyses was set at $\alpha \leq .10$, because of the small sample sizes. We also assessed whether there was a difference in the number of motivated versus unmotivated and competent versus incompetent adolescents from admission to departure by using the McNemar test.

Treatment satisfaction was analyzed by descriptive analysis. Differences between the five dimensions of treatment satisfaction were assessed by using the Friedman's ANOVA test. Because of the small sample size, we applied a threshold for significance at $\alpha \leq .10$. For the post hoc analyses with the Wilxocon signed-rank test we applied a Bonferroni correction, which resulted in $\alpha \leq .01$ as a threshold for significance.

To determine whether the adolescents' motivation for treatment and the quality of client-staff relationship were associated with outcomes in terms of change in motivation 
for treatment, competence skills and treatment satisfaction, we conducted univariate analyses by applying Mann-Whitney tests and correlation analyses. We conducted a Kruskal-Wallis test to assess differences between the four risk groups. For these analyses, we also applied a threshold for significance at $\alpha \leq .10$. By using the Bonferroni correction the threshold for significance for the post hoc analyses with the Mann-Whitney test was set at $\alpha \leq .017$.

The statistical program that we used to perform these analyses was SPSS, PASW Statistics 18.0.3.

\section{Results}

\section{Change in Treatment Motivation and Competence}

The change in motivation for treatment and competence skills of the adolescents are shown in Table 3.

According to group care workers there was no significant change in competence skills of the adolescents during their stay in the center. Adolescents reported an increase in the preparation stage score of motivation for treatment from admission to departure $(T=51.5$, $p=.081)$, which could be considered as a medium effect $(r=.26)$. Two more adolescents (9\%) could be considered motivated for treatment at departure than at admission. Furthermore, there were three more adolescents $(11 \%)$ that could be perceived as sufficiently competent at departure while they were perceived as incompetent at admission, but the McNemar tests showed no significant differences in competence from admission to departure.

Table 3 Change in adolescents' motivation for treatment and competence from $T_{1}$ to $T_{3}$

\begin{tabular}{llllll}
\hline Variable & \multicolumn{2}{l}{ Admission $\left(\mathrm{T}_{1}\right)$} & & \multicolumn{2}{c}{ Departure $\left(\mathrm{T}_{3}\right)$} \\
\cline { 2 - 3 } & $M$ & & & $M$ & SD \\
\hline Motivation for treatment $(n=22)$ & 6.08 & 2.27 & & 6.88 & 1.91 \\
Stage 1 Precontemplation & 1.32 & 0.58 & & 1.31 & 0.59 \\
Stage 2 Contemplation & 0.79 & 0.63 & & 0.73 & 0.50 \\
Stage 3 Preparation ${ }^{\dagger}$ & 1.06 & 0.61 & & 1.37 & 0.61 \\
Competence skills $(n=27)$ & 3.07 & 0.56 & & 3.07 & 0.43 \\
Peer relationships & 3.05 & 0.56 & & 3.05 & 0.52 \\
Autonomy and self-management & 2.91 & 0.61 & & 3.01 & 0.51 \\
Academic competence & 3.03 & 0.75 & & 2.91 & 0.81 \\
Job competence & $2.71^{\mathrm{a}}$ & 1.04 & & 2.97 & 0.98 \\
Sexuality and relationships & $3.13^{\mathrm{b}}$ & 0.83 & & 2.88 & 0.68 \\
Personal hygiene and well-being & 3.36 & 0.66 & & 3.35 & 0.42 \\
\hline
\end{tabular}

The total motivation for treatment scores ranges from 0 to 12 and the three subscales scores from 0 to 2 . Competency scores range from 1 to 5 . Higher scores can be perceived as a higher motivation for treatment and more competence skills. A motivation score $\geq 6,5$ and a competence score $\geq 3$ is perceived as sufficient. Changes from admission to departure have been calculated by using the Wilcoxon signed-rank test

${ }^{\mathrm{a}} n=26,{ }^{\mathrm{b}} n=24$

${ }^{\dagger} p \leq .10$ 
Treatment Satisfaction

The satisfaction scores of the 51 adolescents about the care they received are shown in Table 4.

The adolescents only just reported sufficient satisfaction regarding the care they received, indicated by the average report mark of 5.5. They were the least satisfied with regard to the course of treatment and the most satisfied about the expertise of staff. By applying the cut-off score for sufficient treatment satisfaction, 33 adolescents $(65 \%)$ could be perceived as satisfied and 18 adolescents $(35 \%)$ as unsatisfied regarding the care received.

We found a significant difference between the dimensions of treatment satisfaction, $\chi^{2}(4)=13.3, p=.01$. Post hoc analyses showed that the adolescents were significantly less satisfied about the course of treatment than the expertise of staff, $r=-.49, p=.000$, and the contact and treatment by staff, $r=-.43, p=.002$.

\section{Treatment Motivation and Adolescent-Staff Relationship Association with Outcomes}

The results of the univariate analyses between client and care factors and outcomes in terms of change in motivation for treatment and competent functioning during secure care are shown in Table 5.

The results showed that adolescents who report to be better motivated for treatment at admission were likely to report deterioration in their motivation score from admission to departure. The Kruskal-Wallis test showed no significant differences in treatment motivation or competence skills change during care between the low risk, individual risk, individual and family risk, and high risk group.

The results of the univariate analyses between client and care factors and treatment satisfaction are shown in Table 6.

A higher motivation for treatment level at admission was significantly associated with more treatment satisfaction. A positive relationship with the coach was associated with more treatment satisfaction according to both the adolescents and coaches, but this did not apply to the relationship between adolescents and mentors. The Kruskal-Wallis test showed a significant difference between the low risk, individual risk, individual and family risk, and high risk group in terms of satisfaction about the course of treatment, $H(3)=7.20, p=.07$. Post hoc analyses with the Mann-Whitney test indicated no

Table 4 Adolescents' satisfaction about the care received $(\mathrm{n}=51)$

\begin{tabular}{llr}
\hline Variable & $M$ & SD \\
\hline Overall treatment satisfaction & 2.68 & 0.62 \\
Contact and treatment by staff & 2.75 & 0.63 \\
Expertise staff & 2.80 & 0.70 \\
Course of treatment & 2.46 & 0.89 \\
Receipt of information during care $^{\text {Goal attainment }}{ }^{\mathrm{a}}$ & 2.73 & 0.57 \\
Report mark treatment satisfaction $^{\mathrm{b}}$ & 2.64 & 0.78 \\
\hline
\end{tabular}

Satisfaction scores range from 1 (poor) to 4 (good) and the report marks from 1 to 10 . An overall mean satisfaction score $\geq 2.5$ and report marks of 5,5 and higher are perceived as sufficient

${ }^{\text {a }} n=50,{ }^{\text {b }} n=49$ 
Table 5 Correlations between adolescents' treatment motivation, adolescent-staff relationship and outcomes

\begin{tabular}{|c|c|c|c|c|c|c|c|c|c|c|}
\hline \multirow[t]{3}{*}{ Outcome variable } & \multicolumn{10}{|c|}{ Client-staff relationship } \\
\hline & \multicolumn{2}{|c|}{$\begin{array}{l}\text { Motivation for } \\
\text { treatment }\end{array}$} & \multicolumn{2}{|c|}{$\begin{array}{l}\text { Adolescent- } \\
\text { coach }\end{array}$} & \multicolumn{2}{|c|}{$\begin{array}{l}\text { Coach- } \\
\text { adolescent }\end{array}$} & \multicolumn{2}{|c|}{$\begin{array}{l}\text { Adolescent- } \\
\text { mentor }\end{array}$} & \multicolumn{2}{|c|}{$\begin{array}{l}\text { Mentor- } \\
\text { adolescent }\end{array}$} \\
\hline & $r_{(s)}$ & $n$ & $r_{(s)}$ & $n$ & $r_{(s)}$ & $n$ & $r_{(s)}$ & $n$ & $r_{(s)}$ & $n$ \\
\hline Motivation $\mathrm{T}_{1}-\mathrm{T}_{3}$ & $-.61 * *$ & 22 & -.06 & 21 & .08 & 15 & .05 & 19 & -.10 & 15 \\
\hline Stage 1 Precontemplation & -.17 & 22 & .05 & 21 & .02 & 15 & .33 & 19 & .15 & 14 \\
\hline Stage 2 Contemplation & -.24 & 22 & .32 & 21 & .03 & 15 & .04 & 19 & .04 & 15 \\
\hline Stage 3 Preparation & $-.50^{*}$ & 22 & -.22 & 21 & -.03 & 15 & .05 & 19 & -.29 & 14 \\
\hline Competence $T_{1}-T_{3}$ & .00 & 16 & .25 & 21 & -.14 & 23 & -.03 & 19 & -.14 & 21 \\
\hline
\end{tabular}

Associations have been calculated by using Spearman's correlation coefficients. A positive correlation means that the higher the variable score, the higher the positive change score is. The adolescent-coach and adolescent-mentor rows apply to the relationship as perceived by the adolescents. The coach- and mentoradolescent relationship is the relationship as perceived by the coach and mentor respectively

$* p \leq .05 . * * p \leq .01$

Table 6 Correlations between adolescents' problems, adolescent-staff relationship and treatment satisfaction

\begin{tabular}{|c|c|c|c|c|c|}
\hline \multirow[t]{2}{*}{ Outcome variable } & \multicolumn{5}{|c|}{ Client-staff relationship } \\
\hline & $\begin{array}{l}\text { Motivation for } \\
\text { treatment } \\
(n=46) \\
r_{(s)}\end{array}$ & $\begin{array}{l}\text { Adolescent- } \\
\text { coach } \\
(n=50) \\
r_{(s)}\end{array}$ & $\begin{array}{l}\text { Coach- } \\
\text { adolescent } \\
(n=36) \\
r_{(s)}\end{array}$ & $\begin{array}{l}\text { Adolescent- } \\
\text { mentor } \\
(n=46) \\
r_{(s)}\end{array}$ & $\begin{array}{l}\text { Mentor- } \\
\text { adolescent } \\
(n=34) \\
r_{(s)}\end{array}$ \\
\hline Treatment satisfaction & $.37 *$ & $.42 * *$ & $.29^{\dagger}$ & .09 & -.12 \\
\hline Contact and treatment & $.32 *$ & $.38 * *$ & $.29^{\dagger}$ & .08 & -.06 \\
\hline Expertise staff & $.47^{* *}$ & $.24 * *$ & $.28^{\dagger}$ & .16 & -.16 \\
\hline Course of treatment & .23 & $.31 *$ & .24 & .07 & -.23 \\
\hline Information during care & .23 & $.35^{*}$ & .19 & .03 & -.08 \\
\hline Goal attainment & $.46 * *$ & $.44 * *$ & .24 & -.04 & .05 \\
\hline
\end{tabular}

Associations have been calculated by using Spearman's correlation coefficients. A positive correlation means that the higher the variable score, the higher the satisfaction score is. The client-staff relationships represent the same as in Table 5

${ }^{\dagger} p \leq .10 . * p \leq .05 . * * p \leq .01$

significant differences, but a trend for adolescents in the high risk group to be more satisfied about the course of treatment than adolescents in the individual risk group, $U=5.0, r=-.64, p=.02$, and the individual and family risks group, $U=10.5, r=-$ $.53, p=.05$.

\section{Discussion}

The first aim of the present study was to assess the outcomes of secure care in terms of change in the youths' behavior during care and satisfaction about the received care. We assumed that the secure care center would mainly intervene with the problem awareness, 
motivation for treatment and competence skills of the adolescents, because the social competency model (Durrant 1993; Slot and Spanjaard 1999) was considered to be the primary, underlying methodology of the care and treatment in the secure center. In contrast to our expectations, however, the results showed that the adolescents did not show significant changes in their competence skills from admission to departure according to group care workers.

Since research in residential youth care indicates that methods applied by care workers in their contact with clients differ from the methodology that should be used in theory (Andersson and Johansson 2008; Harder et al. 2011a, b), it might be that the social competency model in the center was less consistently applied in practice than in theory. This lack of program integrity might have caused the intervention not to intervene on the competence skills of the adolescents, as was expected beforehand. Research that specifically focused on the implementation of new methods in Dutch juvenile justice institutions supports this idea by showing that a good implementation of methods is difficult (Beenker and Bijl 2003; Hendriksen-Favier et al. 2010). Another explanation for the finding is that group care workers are critical in their assessment of adolescents' behavioral progress during care (cf. Knorth et al. 2008), and therefore, did not observe significant changes in the adolescents' competence skills. It might be that young people themselves do think that they have progressed in their skills during care. For example, a recent study that focused on the skills of young people at the moment of departure from residential care showed, in contrast to the expectations of the authors, that these young people reported that they did have the necessary skills to be successful after their departure (Casey et al. 2010).

More consistent with our expectations is the finding that adolescents reported a positive change in the preparation stage of motivation for treatment from admission to departure. This indicates that more adolescents were intending to take action in the near future (Prochaska et al. 1993). The medium effect size $(r=.26)$ that we found for the improvement in one of the treatment motivation stages during secure residential care corresponds to the moderate improvements $(d=.45-.60)$ in young people's behavior problems that were found in a meta-analysis of empirical studies within the context of residential youth care (Knorth et al. 2008). Within the context of secure residential youth care, a Dutch study of Boendermaker (1998) found a higher effect size $(d=1.15)$ with regard to the reduction of externalizing behavioral problems of adolescents during care. This suggests that the effect size for treatment motivation that we found is rather small and might be improved.

Our findings suggest that the adolescents' treatment motivation improved during secure residential care (Van Binsbergen 2003). However, it does not become clear how and why their motivation for treatment was improved. The transtheoretical model of change of Prochaska and Diclemente (1984), which was the basis for the instrument that we used, assumes that behavioral change occurs in a series of discrete stages, while little empirical support has been found for these stages of change (see Littell and Girvin 2002). In other residential youth care studies, treatment motivation is defined as the motivation of young people to engage in treatment (Englebrecht et al. 2008; Raftery et al. 2010; Smith et al. 2008). For example, Raftery et al. (2010) found that engagement in treatment, as reported by the young people in residential care, was an important predictor of improvements that were found in youth problem-solving skills. Engagement in treatment might be a more appropriate way of defining treatment motivation. However, treatment engagement is a construct that includes both the youths' attitude about treatment, participation in treatment and relationship with providers (Cunningham et al. 2009; Yatchmenoff 2005), while clients' willingness to participate and the client-staff relationship in treatment seem to be important, distinct constructs in association with outcomes (cf. Karver et al. 2006). 
Overall, the outcome in terms of adolescents' treatment satisfaction was only just sufficient. This indicates that it is necessary to make improvements in the secure residential care process. Considering the specific care aspects, adolescents were the least satisfied about the course of treatment and the goals and results that could be attained. This finding can be explained by the nature of the care they received, since these adolescents were often placed under coercion in the secured environment of the residential setting. Research has shown that young people who perceive there is a good reason for placement show higher levels of engagement in treatment than young people who do not perceive a good reason for placement (Englebrecht et al. 2008). In addition, almost all the adolescents in our sample had received other types of care prior to their admission to the secure care center, which makes that these young people are "experienced" in (residential) care and this might have influenced their expectations about care in a negative way (cf. Harder et al. 2007; Lodewijks 2007). These findings point to the need for secure residential care settings to explicitly pay attention to the adolescents' perspectives regarding their placement and their previous care experiences. Furthermore, goal-oriented working and creating a perspective for these adolescents should be explicit aspects of care, because these are factors that can motivate young people for treatment (Klomp et al. 2004; Van Binsbergen 2003).

The second aim of the present study was to identify whether and how adolescents' behavior problems and the client-staff relationship were associated with outcomes of secure care. With regard to adolescents' problems, we found that adolescents who reported to be better motivated for treatment at admission showed deterioration in their treatment motivation during their stay. This unexpected result might be explained by a possible ceiling effect for treatment motivation, which limits the amount of change that can be shown by the adolescents who were already motivated for treatment at the moment of admission, or by regression toward the mean due to error in the measure (Kazdin 2003). Another possibility is that adolescents who were motivated at admission became less motivated due to a lack of perspective within the secure residential care context (see also the discussion in the previous section). Also in contrast to our expectations was the finding that the four risk groups which we found in a previous study within the present sample of adolescents (Harder et al. 2011a, b) did not significantly differ in terms of achieved outcomes. This result can be explained by the lack of power to detect differences (see also the limitations discussed hereafter). On the other hand we did found, in line with our expectations, that a higher motivation for treatment level at admission was significantly associated with more treatment satisfaction.

Positive relationships with staff were, in contrast to our expectations, not associated with improvements in adolescents' motivation for treatment or competence. This can be explained by the fact that we found small changes with regard to motivation for treatment and no significant changes in competence from admission to departure. A positive relationship with the group care worker, but not with the teacher, was associated with more treatment satisfaction according to both the adolescents and group care workers. For adolescents goal attainment was the most important care aspect that was associated with a positive relationship and this seems to be consistent with the finding of Holmqvist et al. (2007) that adolescents seem to prefer staff with a clear focus on work or tasks rather than staff without such a clear focus. We also found that a positive adolescent-staff relationship was related to adolescents' satisfaction with contact and treatment by staff and expertise of staff according to group care workers. This finding corresponds to results of other studies that treatment skills of staff, i.e. mainly interpersonal and direct influence skills, are important for achieving positive outcomes in youth treatment (Karver et al. 2006). 
Limitations

A limitation of the present study is that a part of the results is based on relatively small subsamples of adolescents due to attrition, especially with regard to questionnaires that were completed on two measurements in time. Therefore, the results may not generalize to all adolescents in the population, because we have found indications that adolescents who completed questionnaires seem to function relatively better than adolescents who did not. The small subsamples and missing data also limited the analysis methods that could be applied. For example, we only used univariate analysis to examine the associations between independent and dependent variables. Since it is more desirable to apply analyses that include several variables in one model so that interaction effects can be detected, future research on this topic should include a larger study sample. In doing so, missing data might be prevented by using interviews rather than questionnaires with both adolescents and staff members in secure residential care.

Another important limitation of the study is that we used a repeated measures research design. This design does not allow for making causal inferences since we did not use a control group. For example, the significant change that we found in the adolescents' treatment motivation from admission to departure does not necessarily have to be caused by the intervention that the adolescents received. It might be that there were other factors that influenced the adolescents' treatment motivation, such as events that happened in the adolescents' contexts (e.g., development of positive relationship with parents during secure care) or processes within the adolescents themselves (e.g., being better "adapted" to the secure residential environment) (Kazdin 2003; Marsh et al. 2010). Moreover, the presented associations between treatment motivation, the adolescent-staff relationship and outcomes do not give an indication for the direction in which these variables are connected. Studies with a (quasi-) experimental design are needed to be able to determine the exact directions of the associations between potential success factors and outcomes of secure residential care.

\section{Conclusion and Implications}

Although our study has limitations, the results suggest that some aspects of the adolescent's treatment motivation increased during secure residential care. The results also suggest that the relationship with group care workers is important in association with treatment satisfaction of the adolescents. Since recent research indicates that changes in problem behavior trajectories during care function as important predictors for outcomes after the young people's departure from residential care (Lee et al. 2010), more in-depth research on the process of change for adolescents in secure residential youth care is needed. Within the context of residential care research, more attention should be paid to the experiences of adolescents during care so that it becomes clear which aspects can and should be improved (e.g., Abrams 2006). Our results suggest that outcomes might get better by a more clear treatment focus on improving the adolescent's treatment motivation (e.g., by paying explicit attention to adolescents' previous care experiences, perspectives of adolescents regarding their placement, goal-oriented activities and by creating a perspective for the adolescents during care) and on the quality of the adolescent-care worker relationship during secure residential care.

Acknowledgments We would like to acknowledge the staff members at Het Poortje who were instrumental in the data collection process. This project was partly supported by secure care center Het Poortje. 
Conflict of interest The authors declare that they have no conflict of interest.

Open Access This article is distributed under the terms of the Creative Commons Attribution Noncommercial License which permits any noncommercial use, distribution, and reproduction in any medium, provided the original author(s) and source are credited.

\section{References}

Abrams, L. S. (2006). Listening to juvenile offenders: Can residential treatment prevent recidivism? Child and Adolescent Social Work Journal, 23(1), 61-85. doi:10.1007/s10560-005-0029-2.

American Psychological Association. (2002). Ethical principles of psychologists and code of conduct. American Psychologist, 57(12), 1060-1073. doi:10.1037/0003-066X.57.12.1060.

Andersson, B., \& Johansson, J. (2008). Personal approaches to treatment among staff in residential care. Journal of Social Work, 8(2), 117-134. doi:10.1177/1468017307088493.

Beenker, L. G. M., \& Bijl, B. (2003). From implementation to realization. A first evaluation of the implementation of the competence model in four judicial youth institutions. Duivendrecht: PI Research (in Dutch).

Bettmann, J., \& Jasperson, R. (2009). Adolescents in residential and inpatient treatment: A review of the outcome literature. Child \& Youth Care Forum, 38(4), 161-183. doi:10.1007/s10566-009-9073-y.

Boendermaker, L. (1998). All's well that ends well? The living conditions of youth a year after departing from a secure treatment facility. The Hague: WODC (in Dutch).

Bullock, R., Little, M., \& Millham, S. (1998). Secure treatment outcomes: The care careers of very difficult adolescents. Aldershot, UK: Ashgate.

Carr, A. (2009). What works with children, adolescents, and adults? A review of research on the effectiveness of psychotherapy. London: Routledge.

Casey, K., Reid, R., Trout, A., Hurley, K., Chmelka, M., \& Thompson, R. (2010). The transition status of youth departing residential care. Child \& Youth Care Forum, 39(5), 323-340. doi:10.1007/s10566010-9106-6.

Cunningham, W. S., Duffee, D. E., Huang, Y., Steinke, C. M., \& Naccarato, T. (2009). On the meaning and measurement of engagement in youth residential treatment centers. Research on Social Work Practice, 19(1), 63-76. doi:10.1177/1049731508314505.

DeMatteo, D., \& Marczyk, G. (2005). Risk factors, protective factors, and the prevention of antisocial behavior among juveniles. In K. Heilbrun, N. E. S. Goldstein, \& R. E. Redding (Eds.), Juvenile delinquency: Prevention, assessment, and intervention (pp. 19-44). New York: Oxford University Press.

Durrant, M. (1993). Residential treatment: A cooperative, competency-based approach to therapy and program design. New York: W. W. Norton \& Company.

Englebrecht, C., Peterson, D., Scherer, A., \& Naccarato, T. (2008). "It's not my fault": Acceptance of responsibility as a component of engagement in juvenile residential treatment. Children and Youth Services Review, 30(4), 466-484. doi:1016/j.childyouth.2007.11.005.

Florsheim, P., Shotorbani, S., Guest-Warnick, G., Barratt, T., \& Hwang, W. C. (2000). Role of the working alliance in the treatment of delinquent boys in community-based programs. Journal of Clinical Child Psychology, 29(1), 94-107. doi:10.1207/S15374424jccp2901_10.

Garcia, J. A., \& Weisz, J. R. (2002). When youth mental health care stops: Therapeutic relationship problems and other reasons for ending youth outpatient treatment. Journal of Consulting and Clinical Psychology, 70(2), 439-443.

Genovés, G. V., Morales, A. L., \& Sánchez-Meca, J. (2006). What works for serious juvenile offenders? A systematic review. Psicothema, 18(3), 611-619.

Grietens, H., \& Hellinckx, W. (2004). Evaluating effects of residential treatment for juvenile offenders by statistical meta-analysis: A review. Aggression \& Violent Behavior, 9(4), 401-415. doi:10.1016/ S1359-1789(03)00043-0.

Harder, A. T., Kalverboer, M. E., \& Knorth, E. J. (2007). The inside out: An exploratory study of the target group and care program of secure residential care facility Het Poortje. Groningen: University of Groningen (internal report; in Dutch).

Harder, A. T., Kalverboer, M. E., \& Knorth, E. J. (2011b). Interaction within the black box: A review of relationships between clients and staff in residential youth care (in preparation).

Harder, A. T., Knorth, E. J., \& Kalverboer, M. E. (2011a). Risky or needy? Characteristics of adolescents in secure residential youth care (submitted). 
Harder, A. T., Knorth, E. J., \& Zandberg, T. (2006). Residential youth care in the picture: A review study of its target group, methods and outcomes. Amsterdam: SWP Publishers (in Dutch).

Hendriksen-Favier, A., Place, C., \& Van Wezep, M. (2010). Process evaluation of YOUTURN: intake program and stabilization- and motivation period: Phase 1 and 2 of the basis method in juvenile justice institutions. Utrecht: Trimbos-Instituut (in Dutch).

Holmqvist, R., Hill, T., \& Lang, A. (2007). Treatment alliance in residential treatment of criminal adolescents. Child \& Youth Care Forum, 36(4), 163-178. doi:10.1007/s10566-007-9037-z.

Jurrius, K., Havinga, L., \& Strating, G. (2007). The C-test version 2007: Evaluation C-test version 2004, adjustment and justification. Amsterdam: MOgroep/Stichting Alexander (in Dutch).

Karver, M. S., Handelsman, J. B., Fields, S., \& Bickman, L. (2005). A theoretical model of common process factors in youth and family therapy. Mental Health Services Research, 7(1), 35-51. doi:10.1007/ s11020-005-1964-4.

Karver, M. S., Handelsman, J. B., Fields, S., \& Bickman, L. (2006). Meta-analysis of therapeutic relationship variables in youth and family therapy: The evidence for different relationship variables in the child and adolescent treatment outcome literature. Clinical Psychology Review, 26(1), 50-65. doi:10.1016/j.cpr.2005.09.001.

Kashubeck, S., Pottebaum, S. M., \& Read, N. O. (1994). Predicting elopement from residential treatment centers. American Journal of Orthopsychiatry, 64(1), 126-135.

Kazdin, A. E. (2003). Research design in clinical psychology. Boston, MA: Allyn and Bacon.

Klingsporn, M. J., Force, R. C., \& Burdsal, C. (1990). The effectiveness of various degrees and circumstances of program completion of young male offenders in a residential treatment center. Journal of Clinical Psychology, 46(4), 491-500.

Klomp, M., Kloosterman, P., \& Kuijvenhoven, T. (2004). Get going: Motivating young people to break out of deadlock. Amsterdam: SWP Publishers.

Knorth, E. J., Harder, A. T., Zandberg, T., \& Kendrick, A. J. (2008). Under one roof: A review and selective meta-analysis on the outcomes of residential child and youth care. Children and Youth Services Review, 30(2), 123-140. doi:10.1016/j.childyouth.2007.09.001.

Lee, B. R., Chmelka, M. B., \& Thompson, R. (2010). Does what happens in group care stay in group care? The relationship between problem behaviour trajectories during care and post-placement functioning. Child \& Family Social Work, 15(3), 286-296. doi:10.1111/j.1365-2206.2009.00669.x.

Littell, J. H., \& Girvin, H. (2002). Stages of Change: A critique. Behavior Modification, 26(2), $223-273$. doi:10.1177/0145445502026002006.

Lodewijks, H. (2007). Interventions with young people in judicial treatment facilities: The state of the art. Tijdschrift Voor Psychotherapie, 33(2), 82-101. (in Dutch).

Marsh, S. C., \& Evans, W. P. (2009). Youth perspectives on their relationships with staff in Juvenile correction settings and perceived likelihood of success on release. Youth Violence and Juvenile Justice, 7(1), 46-67. doi:10.1177/1541204008324484.

Marsh, S., Evans, W., \& Williams, M. (2010). Social support and sense of program belonging discriminate between youth-staff relationship types in juvenile correction settings. Child \& Youth Care Forum, 39(6), 481-494. doi:10.1007/s10566-010-9120-8.

Orlando, M., Chan, K., \& Morral, A. (2003). Retention of court-referred youths in residential treatment programs: Client characteristics and treatment process effects. American Journal of Drug and Alcohol Abuse, 29(2), 337-357. doi:10.1081/ADA-120020518.

Prochaska, J. O., \& DiClemente, C. C. (1984). The transtheoretical approach: Crossing traditional boundaries of therapy. Homewood, Ill: Dow Jones-Irwin.

Prochaska, J. O., DiClemente, C. C., \& Norcross, J. C. (1993). In search of how people change: Applications to addictive behaviors. Journal of Addictions Nursing, 5(1), 2-16.

Raftery, J., Steinke, C., \& Nickerson, A. (2010). Engagement, residential treatment staff cognitive and behavioral disputations, and youths' problem-solving. Child \& Youth Care Forum, 39(3), 167-185. doi:10.1007/s10566-010-9093-7.

Ramos, C., Stams, G. J., Stoel, R., Faas, M., Van Yperen, T. A., \& Dekovic, M. (2006). Measuring client satisfaction in youth care. Kind en Adolescent, 27(3), 157-168. (in Dutch).

Robbins, M. S., Turner, C. W., Alexander, J. F., \& Perez, G. A. (2003). Alliance and dropout in family therapy for adolescents with behavior problems: Individual and systemic effects. Journal of Family Psychology, 17(4), 534-544.

Schuengel, C., \& Zegers, M. A. M. (2003). Psychological availiability and reliance on adult manual. Amsterdam/Zetten: Free University Amsterdam/Orthopedagogical center OGH.

Shirk, S. R., \& Karver, M. (2003). Prediction of treatment outcome from relationship variables in child and adolescent therapy: A meta-analytic review. Journal of Consulting and Clinical Psychology, 71(3), 452-464. doi:10.1037/0022-006X.71.3.452. 
Slot, N. W., \& Spanjaard, H. J. M. (1999). Expanding competency in residential child and youth care: Support for children and young people in residential homes and institutions. Baarn: Intro Publishers (in Dutch).

Smith, B. D., Duffee, D. E., Steinke, C. M., Huang, Y., \& Larkin, H. (2008). Outcomes in residential treatment for youth: The role of early engagement. Children and Youth Services Review, 30(12), 1425-1436. doi:10.1016/j.childyouth.2008.04.010.

Sunseri, P. (2001). The prediction of unplanned discharge from residential treatment. Child \& Youth Care Forum, 30(5), 283-303.

Van Binsbergen, M. H. (2003). Motivation for treatment: Development of motivation for treatment in a secure residential facility (Doctoral dissertation). Leiden: University of Leiden (in Dutch).

Van Binsbergen, M. H., Knorth, E. J., Klomp, M., Ruijssenaars, A. J. J. M., \& Meulman, J. J. (2004). Motivation for treatment in judicial youth institutions. In A. Vyt, Van Aken, M. A. C., J. D. Bosch, Van der Gaag, R. J. \& Ruijssenaars, A. J. J. M. (Eds.), Annual Developmental psychology, Orthopedagogics and Child psychiatry 2004-2005 (pp. 35-61). Houten: Bohn Stafleu van Loghum (in Dutch).

Van der Knaap, L. M. (2003). Competency-based assessment of adolescents in residential treatment facilities: Development of a questionnaire (Doctoral dissertation). Amsterdam: PI Research (in Dutch).

Van der Ploeg, J. D., Scholte, E. M., \& Berg, H. H. (2000). Interventions for serious problematic youth. Amsterdam: NIPPO (in Dutch).

Van Yperen, T. (2003). By degrees: Working on the effectiveness of youth care. Utrecht: NIZW (in Dutch).

Yatchmenoff, D. K. (2005). Measuring client engagement from the client's perspective in nonvoluntary child protective services. Research on Social Work Practice, 15(2), 84-96. doi:10.1177/ 1049731504271605.

Zegers, M. A. M. (2007). Attachment among institutionalized adolescents: Mental representations, therapeutic relationships and problem behavior (Doctoral dissertation). Amsterdam: University of Amsterdam. 